\title{
INFLUÊNCIA DA GORDURA DO LEITE BOVINO E CAPRINO NA RESISTÊNCIA DO Mycobacterium fortuitum À PASTEURIZAÇÃO LENTA
}

\author{
INFLUENCE OF MILK FAT IN THE RESISTANCE OF Mycobacterium \\ fortuitum TO SLOW PASTEURIZATION
}

\author{
Karina Ramirez Starikoff ${ }^{1^{*}}$ \\ Érika Junko Nishimoto ${ }^{2}$ \\ Fernando Ferreira ${ }^{3}$ \\ Simone Carvalho Balian ${ }^{3}$ \\ Evelise Oliveira Telles ${ }^{3}$
}

\begin{abstract}
${ }^{1}$ Universidade Federal da Fronteira Sul, Laranjeira do Sul, PR, Brasil.
${ }^{2}$ MAPA - Ministério da Agricultura, Pecuária e Abastecimento Laranjeira do Sul, PR, Brasil.

${ }^{3}$ Faculdade de Medicina Veterinária e Zootecnia da Universidade de São Paulo, São Paulo,SP, Brasil

*Autora para contato - karina.starikoff@uffs.edu.br
\end{abstract}

\section{Resumo}

Este estudo objetivou mostrar o efeito da gordura do leite caprino e bovino sobre a resistência térmica do Mycobacterium fortuitum. Amostras de leite foram divididas em duas porções, integral e desnatada, cada porção foi inoculada com $M$. fortuitum e então distribuída em tubos para a quantificação do agente durante a pasteurização lenta, em banho-maria. As amostras foram diluídas e semeadas em Lowenstein-Jensen $\left(37^{\circ} \mathrm{C} / 5\right.$ dias), os resultados da contagem foram expressos em $\log _{10} \mathrm{UFC} / \mathrm{mL}$. O tratamento térmico reduziu 4,4 $\log _{10} \mathrm{UFC} / \mathrm{mL}$ no leite caprino integral (2,8\% de gordura), 4,9 $\log _{10}$ $\mathrm{UFC} / \mathrm{mL}$ no leite caprino desnatado $(0,3 \%), 3,9 \log _{10} \mathrm{UFC} / \mathrm{mL}$ no leite bovino integral $(5,9 \%)$ e 5,4 $\log _{10} \mathrm{UFC} / \mathrm{mL}$ no leite bovino desnatado $(0,2 \%)$, sem diferença significante, possivelmente pelo baixo número de amostras. Os valores $\mathrm{D}_{65}{ }^{\circ} \mathrm{C}$ foram, respectivamente, 10,51 minutos, 8,61 minutos, 18,02 minutos e 7,82 minutos e o valor de $\mathrm{R}^{2}$ baixo das equações da reta indicam que outros fatores, além dos que foram estudados, influenciam a morte térmica do agente. Os resultados sugerem uma tendência de influência da gordura do leite e também da espécie animal sobre a taxa de decaimento do $M$. fortuitum, sendo que a pasteurização foi menos eficaz sobre o M. fortuitum no leite bovino integral.

Palavras-chave: espécie de origem do leite; gordura; micobactéria; morte térmica; redução decimal.

\begin{abstract}
This study aimed to show the effect of goat and bovine milk fat on thermal resistance of Mycobacterium fortuitum. Milk samples were divided into two portions, whole and skimmed, each part was inoculated with $M$. fortuitum and then distributed in tubes for quantification of the agent during pasteurization, in a water bath. As samples were diluted and plated on Lowenstein-Jensen $\left(37^{\circ} \mathrm{C} / 5\right.$ days $)$, the count results were expressed as $\log _{10} \mathrm{CFU} / \mathrm{mL}$. The heat treatment reduced $4.4 \log _{10} \mathrm{CFU} / \mathrm{mL}$ for goat whole milk (2.8\% fat), $4.9 \log _{10} \mathrm{CFU} / \mathrm{mL}$ for skim goat milk (0.3\%), $3.9 \log _{10} \mathrm{CFU} / \mathrm{ml}$ for whole bovine milk (5.9\%), and $5.4 \log _{10} \mathrm{CFU} / \mathrm{mL}$ for skim bovine milk $(0.2 \%)$, without significant difference, possibly because of the low number of samples. Values of $\mathrm{D}_{65}{ }^{\circ} \mathrm{C}$ were, respectively, 10.51 minutes, 8.61 minutes, 18.02 minutes, and 7.82 minutes and the low $\mathrm{R}^{2}$ value of the straight line equations indicated that other factors, in addition to the ones studied, influenced the heat death of the agent. The results suggest a trend of influence by fat milk, and by the animal species on the decay rate of $M$. fortuitum, and that pasteurization was less effective over $M$. fortuitum in whole bovine milk.
\end{abstract}


Keywords: fat content; micobacteria; milk origin species; thermal death.

Enviado em: 28 julho 2012

Aceito em: 05 outubro 2015

\section{Introdução}

O amplo e sistemático emprego da pasteurização do leite reduziu drasticamente a incidência, em humanos, de importantes zoonoses veiculadas por ele, como a tuberculose causada pelo Mycobacterium bovis ${ }^{(1)}$. Os parâmetros de tempo e temperatura da pasteurização foram estabelecidos com base nos estudos conduzidos entre 1920 e 1950 sobre a resistência térmica do Mycobacterium bovis e da Coxiella burnetti ${ }^{(2,3)}$, porque essas são as bactérias não formadoras de esporos mais resistentes ao calor que naturalmente podem contaminar o leite ${ }^{(4)}$. Desde então, poucos estudos foram realizados para atualizar as informações sobre a resistência térmica desses agentes.

Atualmente, os binômios de tratamento térmico aprovados para o leite no Brasil são ${ }^{(5,6)}$ o de 62 a $65^{\circ} \mathrm{C}$ por 30 minutos, denominado de pasteurização lenta e permitido apenas para laticínios de pequeno porte, e o de 72 a $75{ }^{\circ} \mathrm{C}$ por 15 a 20 segundos, denominado de pasteurização rápida. Os dois processos devem inativar a enzima fosfatase alcalina do leite, mas manter a enzima peroxidase ainda ativa, garantindo o atendimento aos parâmetros estabelecidos.

Na década de 1990 foi sugerida a potencial relação do Mycobacterium paratuberculosis com a doença de Crohn em humanos ${ }^{(7)}$, o que desencadeou vários estudos sobre sua resistência à pasteurização do leite ${ }^{(8-15)}$. Em 2002, uma revisão sobre o assunto ${ }^{(16)}$ apontou uma grande variabilidade nos resultados reportados na literatura (de $<2$ a $>10$ reduções decimais em tratamento a $63{ }^{\circ} \mathrm{C} / 30 \mathrm{~min}$., por exemplo). Os autores concluíram que o fato poderia estar relacionado, entre outros fatores, às diferenças entre as cepas empregadas, ao tratamento dado ao inóculo, ao método de pasteurização experimental empregado e ao meio de cultura utilizado para recuperação e contagem do agente.

Nesse particular, há poucos dados na literatura sobre a influência do substrato na curva de morte térmica do Mycobacterium spp. A influência da gordura do leite na cinética de morte térmica não foi avaliada para esta bactéria, embora a literatura indique um efeito protetor para outros microrganismos (17-21). Também não foram encontrados estudos dessa natureza em outros tipos leite, além do bovino, mas há relato de que a termorresistência de Listeria monocytogenes é maior em leite ovino que em bovino e caprino, sugerindo que haja algum componente protetor intrínseco ao leite de ovelha para esse agente ${ }^{(19)}$.

Esses fatos reforçam a importância de atualização dos dados de morte térmica do Mycobacterium spp. em leite de várias espécies animais. Houve suficiente evolução na microbiologia, tanto em meios de cultura quanto em métodos de pesquisa nos últimos 50 anos, quando comparado com as condições em que os dados originais de resistência térmica do M. bovis foram obtidos. Esses dados podem contribuir para a análise da segurança que a pasteurização oferece ao leite, permitindo que o Gerenciador do Risco possa decidir sobre a necessidade de aplicar ou alterar as medidas sanitárias para proteger a saúde do consumidor ${ }^{(22)}$.

Com intuito de compreender melhor a tolerância térmica do Mycobacterium spp., este trabalho teve como objetivo verificar a influência da gordura na eficácia da pasteurização lenta em leite bovino e caprino contaminados com Mycobacterium fortuitum.

O leite bovino foi escolhido por ser o mais produzido no Brasil e o caprino porque é recomendado para crianças, idosos, pacientes em recuperação e pessoas alérgicas ao leite bovino, devido à gordura ser mais facilmente digerida e à proteína ser menos alergênica ${ }^{(23,24)}$. A escolha do M. fortuitum foi fundamentada nos fatos de ser a espécie recomendada pela Organização Mundial da Saúde para estudos preliminares com micobactérias por ser menos patogênica, representando menor risco ao operador, e apresentar crescimento rápido ${ }^{(25)}$; por apresentar curva de morte térmica similar ao do $M$. bovis ${ }^{(9)}$, que é a principal espécie zoonótica transmitida pelo leite, entre as micobactérias; por já ter sido isolada de leite cru ${ }^{(26-28)}$ e de leite pasteurizado ${ }^{(28)}$ e por ser considerado um patógeno oportunista (31), embora não haja relato de doença causada por $M$. fortuitum associada à transmissão pelo leite. 


\section{Material e Métodos}

As amostras de leite foram inoculadas com Mycobacterium fortuitum (NCTN 8573) e pasteurizadas utilizando-se o método de tubo-teste. Foram realizadas três repetições em cada substrato: leite caprino (da raça Saanen) integral e desnatado e leite bovino (mestiço da raça Holandesa) integral e desnatado. As amostras de leite foram obtidas do mesmo animal, sabidamente negativo ao teste da tuberculina e sob condições higiênicas; os primeiros jatos foram descartados para realização do teste da caneca de fundo escuro. As amostras foram semeadas em ágar sangue e incubadas por cinco dias a $37{ }^{\circ} \mathrm{C}$ para se avaliar a qualidade microbiológica geral do leite.

O leite cru foi primeiramente analisado quanto ao teor de gordura pelo método de Gerber e quanto à presença das enzimas peroxidase ${ }^{(30)}$ e fosfatase alcalina (Alkaline Phosphatase FS IFCC $37^{\circ} \mathrm{C}$, Ref: 104419910021, DIASYS - Diagnostic Systems International). Então, metade do volume do leite foi desnatado por centrifugação (BECKMAN, J21-21, Minnesota, EUA) a $5000 \mathrm{rpm}$ por 15 minutos a 0 ${ }^{\circ} \mathrm{C}\left(2520{ }^{\circ} \mathrm{G}\right)$ e o teor de gordura foi analisado novamente.

O inóculo utilizado foi padronizado de forma a se obter uma concentração do Mycobacterium fortuitum próxima a $10^{7} \mathrm{UFC} / \mathrm{mL}$ de leite. Mycobacterium fortuitum (NCTN 8573) foi cultivado em meio Löwenstein-Jensen por 5 dias a $37^{\circ} \mathrm{C}$. Os tubos foram pesados em balança de precisão e, por diferença de peso, aproximadamente $600 \mathrm{mg}$ foram coletados com uma haste de plástico estéril e transferidos para cadinho estéril, sendo vigorosamente macerados com $1 \mathrm{~mL}$ de solução salina $0,85 \%$ com $0,05 \%$ de Tween 80 . Em seguida, foram adicionados $24 \mathrm{~mL}$ de solução salina $0,85 \%$ até completar $25 \mathrm{~mL}$ de volume de inóculo, que foi transferido para erlenmeyer estéril com presença de pérolas de vidro.

O uso do Tween 80, a movimentação vigorosa e as pérolas de vidro visam evitar a formação de grumos, devido à tendência de aglomeração das micobactérias em meios líquidos, por causa da natureza hidrofóbica da sua parede celular ${ }^{(31)}$.

Dois mililitros do inóculo foram adicionados a $50 \mathrm{~mL}$ de leite e, após homogeneização, 5 mililitros foram distribuídos em cada um de oito tubos (16x160 mm com tampa de rosca) previamente identificados com números de 1 a 8 . Os sete primeiros foram usados para o tratamento térmico e o oitavo para a análise da carga inicial ("Ci") do M. fortuitum.

As amostras 1 a 7 foram acondicionadas em banho-maria (BM) à $85^{\circ} \mathrm{C}$ até o leite atingir $65^{\circ} \mathrm{C}$ (fase de aquecimento). Nesse momento, a amostra 1 foi retirada e resfriada, para a contagem no início da pasteurização ("CIP”), enquanto as outras foram transferidas para outro BM, à $65{ }^{\circ} \mathrm{C}$, para a manutenção da temperatura. A cada cinco minutos uma amostra foi retirada e resfriada, até completar o processo, ou seja, aos 5, 10, 15, 20, 25 e 30 minutos, esta última denominada de contagem no final da pasteurização ("CFP") e as intermediárias, "CP5", "CP10" etc.

Três amostras do leite cru não inoculado também foram pasteurizadas com as amostras teste para que, no final do tratamento térmico, fossem realizadas as pesquisas das enzimas peroxidase e fosfatase alcalina ${ }^{(30)}$. Um termômetro de mercúrio foi acoplado a uma quarta amostra de leite cru não contaminado para o monitoramento da temperatura do leite durante a pasteurização. Essas quatro amostras tinham o mesmo volume de leite e estavam acondicionadas no mesmo tipo de tubo que as amostras em teste.

As amostras foram submetidas à diluição decimal seriada em solução salina $0,85 \%$. Depois de serem homogeneizadas em vortex por 10 segundos, $0,1 \mathrm{~mL}$ de cada diluição foi semeado em placas com meio Löwenstein-Jensen em duplicatas e incubado por 5 dias à $37^{\circ} \mathrm{C}$.

A diluição de eleição para a contagem foi a que apresentou entre 15 e 150 colônias. Quando o nível de contaminação foi inferior a 15, na menor diluição, registrou-se a quantidade detectada. Os resultados foram expressos em $\log _{10} \mathrm{UFC} / \mathrm{mL}$.

Utilizou-se o Mann-Whitney Test para se comparar o efeito do substrato na sobrevivência do $M$. fortuitum ao processo térmico.

Uma linha de regressão linear foi utilizada para ajustar o número de registro de sobreviventes no leite em função do tempo. A equação da reta foi utilizada para calcular o valor $\mathrm{D}_{65}{ }^{\circ} \mathrm{C}$ do leite de cabra integral e desnatado, bem como do leite de vaca integral e desnatado. $\mathrm{O}$ valor $\mathrm{D}$ refere-se ao tempo em minutos, à uma dada temperatura, capaz de reduzir um ciclo logarítmico de um micro-organismo. 


\section{Resultados}

O tratamento térmico do leite, praticado no BM em condições que buscavam mimetizar a pasteurização, atendeu aos requisitos enzimáticos oficiais brasileiros: as enzimas fosfatase alcalina e peroxidase estavam ativas no leite cru e apenas a peroxidase permaneceu ativa no leite pasteurizado ${ }^{(5)}$. $\mathrm{O}$ desnate das amostras de leite reduziu o teor de gordura para níveis abaixo de $0,5 \%$ (Tabela 1 ), atendendo aos parâmetros legais para o leite desnatado ${ }^{(6)}$.

A carga inicial $(\mathrm{Ci})$ do $M$. fortuitum $\left(\log _{10} \mathrm{UFC} / \mathrm{mL}\right)$ nas amostras de leite, bem como a contagem dos sobreviventes no início da pasteurização (CIP) e no final (CFP) estão apresentados na Tabela 1. Observou-se que não houve desvitalização completa do inóculo em nenhuma amostra, embora tenha ocorrido um importante decaimento na população microbiana ao final do processo térmico.

A eficácia do processo de pasteurização pode ser compreendida como a somatória do decaimento nas fases de aquecimento (que variou de 59 a 66 segundos, independentemente de ser integral ou desnatado) e de manutenção da temperatura, cujos resultados foram calculados, respectivamente, pela diferença entre as contagens no início e no fim da referida fase: "Ci-CIP" e "CIP - CFP" (Tabela 2). Assim, em média, houve um decaimento total de 4,4 $\log _{10} \mathrm{UFC} / \mathrm{mL}$ no leite caprino integral, de 4,9 $\log _{10} \mathrm{UFC} / \mathrm{mL}$ no leite caprino desnatado, de 3,9 $\log _{10} \mathrm{UFC} / \mathrm{mL}$ no leite bovino integral, de 5,4 $\log _{10}$ $\mathrm{UFC} / \mathrm{mL}$ no leite bovino desnatado e não houve diferença significativa entre essas medidas.

$\mathrm{O}$ valor $\mathrm{D}_{65}{ }^{\circ} \mathrm{C}$ obtido para o leite de cabra integral e desnatado foi, respectivamente, 10,51 e 8,61 minutos. Já para o leite de vaca integral e desnatado foi, respectivamente, 18,02 e 7,82 minutos. As curvas dos sobreviventes e as respectivas equações das retas estão apresentadas na Figura 1.

Tabela 1: Mycobacterium fortuitum em leite experimentalmente contaminado submetido à pasteurização lenta em banho-maria

\begin{tabular}{|c|c|c|c|c|c|}
\hline & Amostra & $\begin{array}{c}\text { Gordura } \\
(\%)\end{array}$ & $\begin{array}{c}\text { Carga inicial } \\
\left(\log _{10}\right. \\
\text { UFC/mL) }\end{array}$ & $\begin{array}{c}\text { Contagem no } \\
\text { início da } \\
\text { pasteurização } \\
\left.\text { (Log } \log _{10} \mathrm{UFC} / \mathrm{mL}\right)\end{array}$ & $\begin{array}{c}\text { Contagem no } \\
\text { final da } \\
\text { pasteurização } \\
\text { (Log } \log _{10} \\
\text { UFC/mL) }\end{array}$ \\
\hline \multirow{8}{*}{$\begin{array}{c}\text { Leite } \\
\text { caprino }\end{array}$} & Integral - 1 & 2,0 & 6,1 & 6,1 & 2,4 \\
\hline & Integral - 2 & 3,2 & 7,8 & 7,2 & 2,8 \\
\hline & Integral - 3 & 3,2 & 7,3 & 7,1 & 2,8 \\
\hline & média & 2,8 & 7,1 & 6,8 & 2,7 \\
\hline & $\begin{array}{c}\text { Desnatado - } \\
1\end{array}$ & 0,3 & 7,2 & 7,4 & 2,0 \\
\hline & $\begin{array}{c}\text { Desnatado - } \\
2\end{array}$ & 0,3 & 7,8 & 7,0 & 2,9 \\
\hline & $\begin{array}{c}\text { Desnatado - } \\
3\end{array}$ & 0,3 & 7,4 & 6,9 & 2,9 \\
\hline & média & 0,3 & 7,5 & 7,1 & 2,6 \\
\hline \multirow{8}{*}{$\begin{array}{c}\text { Leite } \\
\text { bovino }\end{array}$} & Integral - 1 & 5,8 & 6,8 & 4,3 & 2,2 \\
\hline & Integral - 2 & 6,0 & 6,8 & 4,6 & 3,0 \\
\hline & Integral - 3 & 6,0 & 5,8 & 4,4 & 2,5 \\
\hline & média & 5,9 & 6,5 & 4,4 & 2,6 \\
\hline & $\begin{array}{c}\text { Desnatado - } \\
1\end{array}$ & 0,2 & 7,2 & 6,8 & 2,5 \\
\hline & $\begin{array}{c}\text { Desnatado - } \\
2\end{array}$ & 0,2 & 7,2 & 6,9 & 1,6 \\
\hline & $\begin{array}{c}\text { Desnatado - } \\
3\end{array}$ & 0,2 & 7,0 & 6,8 & 1,0 \\
\hline & média & 0,2 & 7,1 & 6,8 & 1,7 \\
\hline
\end{tabular}


Tabela 2: Decaimento de Mycobacterium fortuitum ( $\left.\log _{10} \mathrm{UFC} / \mathrm{mL}\right)$ em amostras de leite caprino e bovino submetidas à pasteurização lenta em banho-maria

\section{Integral}

Desnatado

Aquecimento Manutenção Aquecimento Manutenção

\begin{tabular}{|c|c|c|c|c|c|}
\hline Amostra & & (até $65^{\circ} \mathrm{C}$ ) & (30 $\mathrm{min})$. & (até $65^{\circ} \mathrm{C}$ ) & (30 $\mathrm{min})$. \\
\hline \multirow{4}{*}{$\begin{array}{c}\text { Leite } \\
\text { caprino }\end{array}$} & 1 & 0,0 & 3,7 & $-0,2$ & 5,4 \\
\hline & 2 & 0,6 & 4,4 & 0,8 & 4,1 \\
\hline & 3 & 0,2 & 4,3 & 0,5 & 4,0 \\
\hline & Média & 0,3 & 4,1 & 0,4 & 4,5 \\
\hline \multirow{4}{*}{$\begin{array}{l}\text { Leite } \\
\text { bovino }\end{array}$} & 1 & 2,5 & 2,1 & 0,4 & 4,3 \\
\hline & 2 & 2,2 & 1,6 & 0,3 & 5,3 \\
\hline & 3 & 1,4 & 1,9 & 0,2 & 5,8 \\
\hline & Média & 2,0 & 1,9 & 0,3 & 5,1 \\
\hline
\end{tabular}

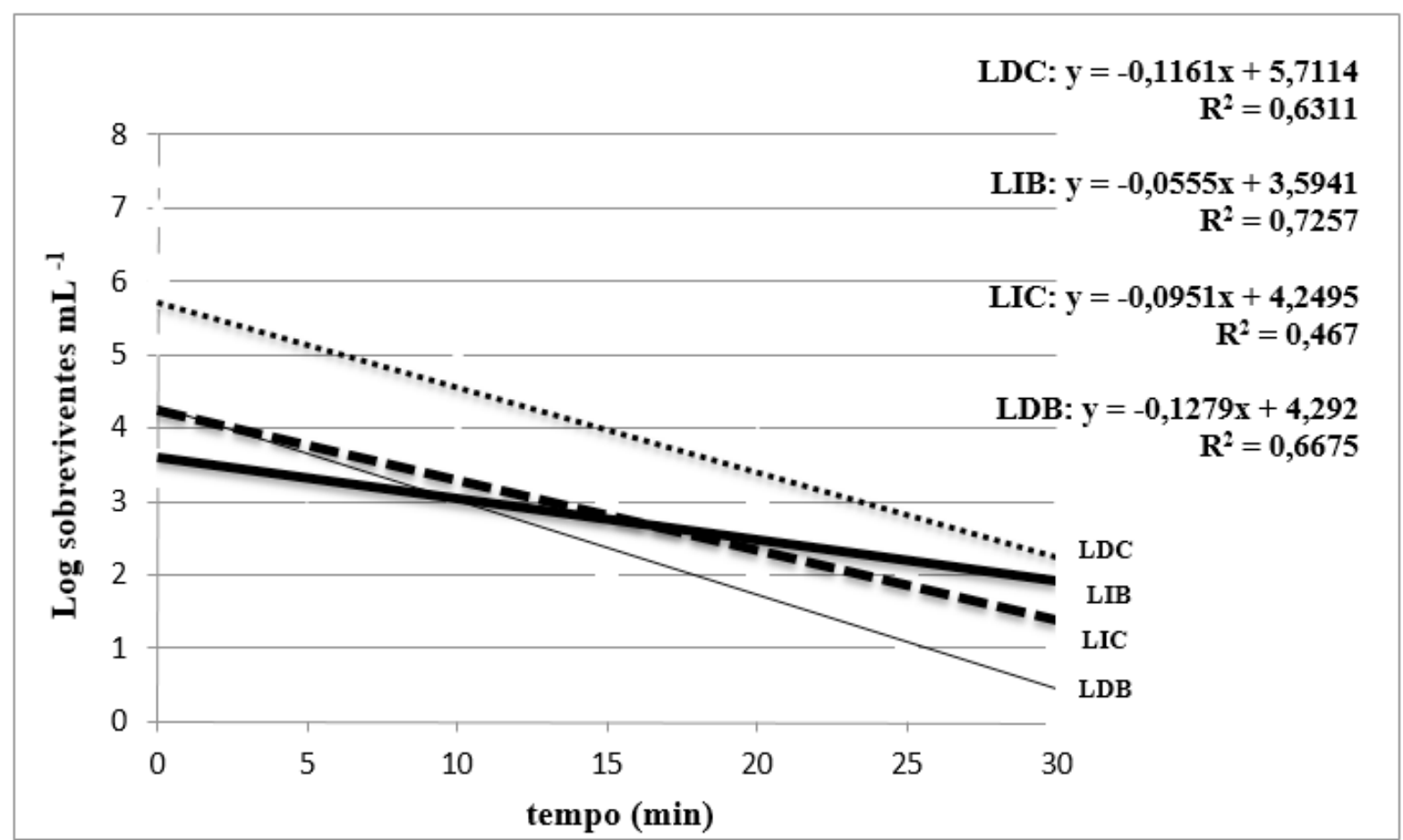

LDC $=$ leite desnatado caprino; LIB $=$ leite integral bovino; LIC $=$ leite integral caprino; LDB $=$ leite desnatado bovino.

Figura 1: Curva de morte térmica $\left(65^{\circ} \mathrm{C}\right)$ do Mycobacterium fortuitum em leite caprino e bovino, integral e desnatado.

\section{Discussão}

O teor de gordura do leite empregado nesta pesquisa esteve fora da média para as duas espécies, mas de modo geral são semelhantes entre si ${ }^{(32,33)}$ e apresentaram-se dentro da variação reportada na literatura. A porcentagem de gordura tende a variar mais que os outros componentes e diferentes fatores exercem influência sobre esta variação, dentre eles estão: raça, alimentação, estação do ano, idade, estágio de lactação e outros efeitos ambientais, que podem explicar os valores obtidos ${ }^{(34,35)}$. 
Tanto a gordura quanto a espécie de origem do leite não tiveram influência significativa sobre o nível de decaimento do M. fortuitum ao tratamento térmico. No entanto, é possível que isso se deva ao baixo número de ensaios realizados em cada substrato $(n=3)$, o que poderia ser esclarecido com novos estudos. Apesar disso, nota-se uma tendência de maiores níveis de decaimento na população do agente em leite desnatado, de ambas as espécies, sugerindo um efeito termo protetor da gordura sobre o $M$. fortuitum, o que não surpreende já que essa propriedade da gordura está bem comprovada na literatura para outras bactérias ${ }^{(17-21)}$.

Ainda na linha de tendências, a gordura teve maior influência no decaimento do $M$. fortuitum no leite bovino do que no leite caprino, o que, a princípio, poderia estar relacionado ao maior teor de gordura nas amostras de leite de vaca $(5,9 \%)$ do que nas de cabra $(2,8 \%)$. É possível, entretanto, que outros fatores tenham contribuído para esse resultado, como a composição do leite em ácidos graxos. O leite caprino é rico em ácidos graxos de cadeia curta e média, como o capróico (C6), caprólico (C8) e cáprico $(\mathrm{C} 10){ }^{(33)}$. A composição percentual desses ácidos são, respectivamente, no leite caprino $0,95 \%, 1,29 \%$ e $5,22 \%$, enquanto no leite bovino são $0,86 \%, 0,59 \%$ e $1,25 \%{ }^{(32)}$.

Outro achado interessante do estudo é que a cinética de morte térmica do $M$. fortuitum no leite bovino integral foi diferente quando comparado com o leite bovino desnatado e leite caprino integral e desnatado. Para o substrato leite bovino integral, a fase de aquecimento foi tão importante para o decaimento da população microbiana quanto os 30 minutos de manutenção da temperatura alvo. Esse fenômeno deve ser mais bem investigado, pois não foram encontrados dados que pudessem sustentar uma teoria plausível.

Dos valores $\mathrm{D}_{65^{\circ} \mathrm{C}}$ obtidos, depreendeu-se que a pasteurização lenta do leite caprino e bovino desnatado seria capaz de reduzir aproximadamente $3 \log _{10} \mathrm{UFC} / \mathrm{mL}$, o que difere da eficácia calculada a partir dos sobreviventes (Tabela 2). Essa diferença de resultado pode estar associada ao fato de que, neste estudo, a função linear não explicou inteiramente a redução dos sobreviventes como função única do tempo de exposição ao calor ( $\mathrm{R}^{2}$ das equações é baixo), diferentemente dos achados de Grant et al ${ }^{(9)}$. Esses autores verificaram um padrão de função linear para as curvas de morte térmica do $M$. bovis e do $M$. fortuitum; vale ressaltar que estes autores utilizaram a técnica de número mais provável para quantificar os agentes.

Comparando-se a influência de dois métodos de quantificação de $M$. paratuberculosis sobre o valor $\mathrm{D}_{62{ }^{\circ}}$, Sung e Collins ${ }^{(10)}$ inocularam o agente em meio lactato. Quando a enumeração foi feita por cultura radiométrica (BACTEC), a curva obtida apresentou $\mathrm{R}^{2}$ igual a 0,95 , mas utilizando-se o método de contagem em placas, o valor de $\mathrm{R}^{2}$ caiu para 0,61 . Este valor é similar aos obtidos nos substratos desnatados do presente estudo, que também utilizou a técnica de contagem em placas, tendo registrado $\mathrm{R}^{2}$ igual a 0,63 no leite caprino e 0,67 no bovino. No leite integral, no entanto, o valor $\mathrm{R}^{2}$ foi ligeiramente mais alto no leite bovino $\left(\mathrm{R}^{2}=0,73\right)$ que no leite caprino $\left(\mathrm{R}^{2}=0,50\right)$. Esses valores baixos de $\mathrm{R}^{2}$ reforçam a hipótese de que outras características como a composição dos ácidos graxos, por exemplo, têm um papel importante na taxa de morte desse agente, além do tempo de tratamento térmico e do teor de gordura do substrato.

Segundo Sung e Collins ${ }^{(10)}$, o valor $\mathrm{D}_{65}{ }^{\circ}$ para M. paratuberculosis em leite foi de 38,9 segundos, cujo teor de gordura não foi especificado, resultado mais baixo que os desta pesquisa. Isso é surpreendente, já que o $M$. fortuitum é considerado menos termo resistente que o M. paratuberculosis ${ }^{(9,10)}$. A divergência pode estar relacionada ao método de quantificação empregado: aqueles autores utilizaram cultura radiométrica (BACTEC) enquanto neste estudo empregou-se contagem em placas. Por fim, outro dado importante é que a pasteurização não causou reduções do $M$. fortuitum para níveis abaixo do detectável pela técnica $(<10 \mathrm{UFC} / \mathrm{mL})$, o que difere dos resultados de Grant et al ${ }^{(9)}$, que não detectaram sobreviventes de M. bovis ou M. fortuitum a $63{ }^{\circ} \mathrm{C}$ por 30 minutos, apesar de também terem partido de $\mathrm{Ci}$ de $7 \log _{10} \mathrm{UFC} / \mathrm{mL}$ no leite.

Considerando-se o fato de que a curva de morte térmica do $M$. fortuitum é análoga à do M. bovis ${ }^{(9)}$ e que o nível de contaminação natural do leite por $M$. bovis pode chegar à $10^{4} \mathrm{UFC} / \mathrm{mL}^{(35)}$, pode-se inferir o impacto da pasteurização sobre esse agente zoonótico.

Aplicando-se os resultados aqui obtidos ao pior cenário de contaminação natural de leite citado por Ball ${ }^{(35)}$, a pasteurização lenta pode não reduzir o $M$. bovis a níveis inferiores a $1 \mathrm{UFC} / \mathrm{mL}$ em leite bovino integral. Esse dado é de difícil interpretação, visto que a literatura é carente em dados sobre dose infectante para esse agente, mas é oportuno considerar que a produção de queijos leva a uma 
provável concentração dos micro-organismos sobreviventes. Os resultados sugerem, no entanto, que a resistência térmica do agente é influenciada pela matriz alimentícia e, desta forma, o assunto precisa ser mais estudado, a fim de se alimentar modelagens de Avaliação de Risco.

\section{Conclusão}

A gordura do leite mostrou efeito protetor sobre o Mycobacterium fortuitum, que foi mais evidente em leite bovino. Além disso, em leite bovino integral, o padrão de decaimento do $M$. fortuitum durante o tratamento térmico diferiu dos demais substratos (leite bovino desnatado e leite caprino integral e desnatado).

\section{Agradecimentos}

Gostaríamos de agradecer à Coordenação de Aperfeiçoamento de Pessoal de Nível Superior (CAPES) pela concessão de bolsa de mestrado e aos técnicos, Sandra Abelardo Sanches e Orlando Bispo de Souza, pela assistência na realização dos experimentos.

\section{Referências}

1.Rowe MT, Donaghy J. Mycobacterium bovis: the importance of milk and dairy products as a cause of human tuberculosis in the UK A review of taxonomy and culture methods, with particular reference to artisanal cheeses. Int J Dairy Technol. 2008; 61(4): 317-326.

2.Huebner RJ, Jellison WL, Beck MD, Wilcox FP. Q fever studies in Southern California: III. Effects of pasteurization on survival of Coxiella burnetti in naturally infected milk. Public Health Rep. 1949; 64: 499511. Disponível em: <http://www.ncbi.nlm.nih.gov/pmc/articles/PMC1996966/> Acesso em agosto de 2015.

3.North CE, Park WH. Standards for milk pasteurization. Am J Hygiene. 1927; 7: 147-173.

4.Cerf O, Condron R. Coxiella burnetti and milk pasteurization: an early application of the precautionary principle? Infect Epidemiol Med. 2006; 134 (5): 946-951. Disponível em: <http://www.ncbi.nlm.nih.gov/ pmc/articles/PMC2870484/pdf/S0950268806005978a.pdf> Acesso em agosto de 2015.

5.Brasil. Ministério da Agricultura, Pecuária e Abastecimento. Decreto 30.691. Aprovação do Regulamento da Inspeção Industrial e Sanitária dos Produtos de Origem Animal. 1952. Available from: http://www.agricultura. gov.br/arq_editor/file/Aniamal/MercadoInterno/Requisitos/RegulamentoInspecaoIndustrial.pdf. Portuguese.

6.Brasil. Ministério da Agricultura, Pecuária e Abastecimento. Instrução Normativa $n^{\circ}$ 62, de 29 de dezembro de 2011. Available from: http://sistemasweb.agricultura.gov.br/sislegis/action/detalhaAto. do? method $=$ consultarLegislacaoFederal. Portuguese.

7.Rudoler N. Is Mycobacterium avium subsp.paratuberculosis an etiological factor in crohn's disease? Refu Vet. 1998; 537-539. Disponível em: < http://www.isrvma.org/ImageToArticle/Files/Vol\%2059_4\%20IS\%20 MYCOBACTERIUM\%20AVIUM\%20SUBSP.doc.> Acesso em agosto de 2015.

8.Chiodini RJ, Taylor JH. The thermal resistance of mycobacterium paratuberculosis in raw milk under conditions simulating pasteurization. J Vet Diagn Invest. 1993; 5: 629-631. Disponível em: < http://www.ncbi. nlm.nih.gov/pubmed/8286469> Acesso em agosto de 2015.

9.Grant IR, Ball HJ, Rowe MT. Thermal inactivation of several Mycobacterium spp. in milk by pasteurization. Lett Appl Microbiol. 1996; 22: 253-256. Disponível em: < http://www.ncbi.nlm.nih.gov/pubmed/8852355> Acesso em agosto de 2015.

10.Sung N, Collins MT. Thermal tolerance of Mycobacterium paratuberculosis. Appl Environ Microbiol. 1998; 64: 999-1005. Disponível em: <http://www.ncbi.nlm.nih.gov/pubmed/9501439> Acesso em agosto de 2015.

11.Stabel JR. On-farm batch pasteurization destroys Mycobacterium paratuberculosis in waste milk. J Dairy Sci. 2001; 84: 524-527. Disponível em: <http://www.ncbi.nlm.nih.gov/pubmed/11233038> Acesso em agosto 
de 2015.

12.Klinjin N, Herrewengh AAPM, Jong P. Heat inactivation data for Mycobacterium avium subsp. paratuberculosis: implications for interpretation. J Food Res. 2001; 9: 697-704. Disponível em: < http://www. ncbi.nlm.nih.gov/pubmed/11576307> Acesso em agosto de 2015.

13.Pearce LE, Truong HT, Crawford RA, Yates GF, Cavaignac S, Lisle GW. Effect of turbulent-flow pasteurization on survival of Mycobacterium avium subsp. paratuberculosis added to raw milk. J Appl Environ Microbiol, 2001; 67(9): 3964-3969. Disponível em: < http://www.ncbi.nlm.nih.gov/pubmed/11525992> Acesso em agosto de 2015.

14.Grant IR, Williams AG, Rowe MT, Muir DD. Efficacy of various pasteurization time-temperature conditions in combination with homogenization on inactivation of Mycobacterium avium subsp. paratuberculosis in milk. J Appl Environ Microbio. 2005; 71(6): 2853-2861. Disponível em: < http://www.ncbi.nlm.nih.gov/ pubmed/15932977> Acesso em agosto de 2015.

15.Mcdonald WL, O'riley KJ, Schroen CJ, Condron RJ. Heat inactivation of Mycobacterium paratuberculosis in milk. J Appl Environ Microbiol. 2005; 71(4): 1785-1789. Disponível em: < http://aem.asm.org/ content/71/4/1785.full> Acesso em agosto de 2015.

16.Lund BM, Gould GW, Rampling AM. Pasteurization of milk and the heat resistance of Mycobacterium avium subsp. paratuberculosis: a critical review of the data. Int J Food Microbiol. 2002; 77: 135-145. Disponível em: $<$ http://www.sciencedirect.com/science/article/pii/S0168160502000570> Acesso em agosto de 2015.

17.Bussata C, Valdruga E, Cansia RL. Occurence of Bacillus sporothermodurans in integral and skimmed UHT milk. Cienc tecnol aliment. 2005; 25 (3): 408-411. Disponível em: < http://dx.doi.org/10.1590/S0101$20612005000300003>$ Acesso em agosto de 2015.

18.Chhabra AT, Carter WH, Linton RT, Cousin MA. A predictive model to determine the effects of $\mathrm{pH}$, milkfat, and temperature on thermal inactivation of Listeria monocytogenes. J Food Prot. 1999; 62 (10): 1143-1149. Disponível em: <http://www.ncbi.nlm.nih.gov/pubmed/10528717> Acesso em agosto de 2015.

19.Macdonald F, Sutherland AD. Effect of heat treatment on Listeria monocytogenes and gram negative bacteria in sheep, cow and goat milk. J Appl Bacteriol. 1993; 75: 336-343. Disponível em: < http://www.ncbi. nlm.nih.gov/pubmed/8226390> Acesso em agosto de 2015.

20.Donnelly CW, Briggs EH. Psychrotrophic growth and thermal inactivation of Listeria monocytogenes as a function of milk composition. J Food Prot. 1986; 49 (12): 994-998.

21.Molin N, Snygg BG. Effect of lipid materials on heat resistance of bacterial spores. Lett Appl Microbiol. 1967; 15: 1422-1426. Disponível em: <http://www.ncbi.nlm.nih.gov/pubmed/16349757> Acesso em agosto de 2015.

22.de Almeida Figueiredo NA, Miranda MS. Análise de Risco aplicada aos alimentos no Brasil: perspectivas e desafios. Ciênc Saúde Col. 2011; 16(4): 2251-2262. Disponível em: <http://www.scielo.br/pdf/csc/v16n4/ v16n4a24.pdf $>$ Acesso em agosto de 2015.

23.Oliveira JM, Hiane PA, Ramos MIL. Características físico-químicas do leite de cabra pasteurizado e congelado, produzido em Campo Grande - MS. Hig. aliment. 2002; 6(102/103): 107-109. Disponível em: < http://saudepublica.bvs.br/pesquisa/resource/pt/lil-340437> Acesso em agosto de 2015.

24.Van Den Heever LW. Tuberculosis in milch goats. J S Afr Vet Assoc. 1984; 55(4), 219-220. Disponível em: $<$ http://www.ncbi.nlm.nih.gov/pubmed/6533312> Acesso em agosto de 2015.

25.Russell AD, Yarnych VS, Koulikovskii A. Guidelines on desinfection in animal husbandry for prevention and control of zoonotic diseases. Geneva: World Health Organization; 1984. 62p. English.

26.Kazwala RR, Daborn CJ, Kusiluka LJM, Jiwa SFH, Sharp JM, Kambarage DM. Isolation of Mycobacterium species from raw milk of pastoral cattle of the Southern Highlands of Tanzania. Trop Anim Health Prod. 1998; 30(4): 233-239. Disponível em: < http://www.ncbi.nlm.nih.gov/pubmed/9760715> Acesso em agosto de 2015.

27.Pardo RB, Langoni H, Mendonca LJP, Chi KD. Isolation of Mycobacterium spp. in milk from cows suspected or positive to tuberculosis. Braz J Vet Res Anim Sci. 2001; 38(6): 284-287. Disponível em: <http:// dx.doi.org/10.1590/S1413-95962001000600007> Acesso em agosto de 2015.

28.Leite CQF, Anno IS, Leite SRA, Roxo E, Morlock GP, Cooksey RC. Isolation and identification of mycobacteria from livestock specimens and milk obtained in Brazil, Mem. Inst. Oswaldo Cruz. 2003; 98(3). 
Disponível em: <http://dx.doi.org/10.1590/S0074-02762003000300005> Acesso em agosto de 2015.

29. Pedro HSP, Pereira MIF, Goloni MRA, Ueki SYM, Chimara E. Isolamento de micobactérias nãotuberculosas em São José do Rio Preto entre 1996 e 2005. J. bras. pneumol. 2008: v.34 n.11 Disponível em: $<$ http://dx.doi.org/10.1590/S1806-37132008001100010 > Acesso em dezembro de 2015.

30. BRASIL. Ministério da Agricultura, Pecuária e Abastecimento. Instrução Normativa $n^{0} 68,12$ de dezembro de 2006. Available from: http://extranet.agricultura.gov.br/sislegis-consulta/consultarLegislacao. do?operacao $=$ visualizar\&id $=17472$

31.Mcfadden JJ, Collins J, Baeman B, Arthur M, Gitnick G. Mycobacteria in Crohn's disease: DNA probes identify the Wood Pigeon strain of Mycobacterium avium and Mycobacterium paratuberculosis from human tissue. J Clin Microbiol. 1992; 30: 3070-3073. Disponível em: < http://www.ncbi.nlm.nih.gov/pmc/articles/ PMC270590/> Acesso em agosto de 2015.

32.Pellegrini LG, Pellegrin ACRS, Gusso AP, Mattanna D, Cassanego DB. Análise do Perfil de Ácidos Graxos do Leite Bovino, Caprino e Ovino. XV Simpósio Paranaense de Ovinocultura, III Simpósio Paranaense de Caprinocultura e III Simpósio Sul Brasileiro de Ovinos e Caprinos, 2012, Pato Branco: Synergismus scyentifica UTFPR; 2012. Disponível em: <http://revistas.utfpr.edu.br/pb/index.php/SysScy/article/viewFile/1511/973> Acesso em agosto de 2015.

33.Pereira RAG, Queiroga RCRE, Vianna RPT, Oliveira MEG. Qualidade química e física do leite de cabra distribuído no Programa Social "Pacto Novo Cariri” no Estado da Paraíba. Rev. Inst. Adolfo Lutz (Impr.) [online]. 2005; 64(2): 205-211. Disponível em: http://periodicos.ses.sp.bvs.br/pdf/rial/v64n2/v64n2a10.pdf Acesso em dezembro de 2015.

34. Oliveira ENA, Santos DC, Oliveira AS, Sousa FC. Composição físico-química de leites em diferentes fases de lactação. Ciênc Agrár Ambient. 2010; 8(4): 409-415. Disponível em: <www2.pucpr.br/reol/index.php/ academica? $d d 99=p d f \& d d 1=4512>$ Acesso em agosto de 2015 .

35. Ball CO. Short-time pasteurization of milk. Ind Eng Chem Res. 1943; 35: 71-84. 